CLINICAL STUDY

\title{
Letrozole once a week normalizes serum testosterone in obesity-related male hypogonadism
}

\author{
Sandra Loves ${ }^{1}$, Janneke Ruinemans-Koerts ${ }^{2}$ and Hans de Boer ${ }^{1}$ \\ Departments of ${ }^{1}$ Internal Medicine and ${ }^{2}$ Clinical Chemistry, Ziekenhuis Rijnstate, Wagnerlaan 55, 6800 TA Arnhem, The Netherlands \\ (Correspondence should be addressed to H de Boer; Email: hdeboer@alysis.nl)
}

\begin{abstract}
Objective: Isolated hypogonadotropic hypogonadism (IHH) is frequently observed in severely obese men, probably as a result of increased estradiol $\left(\mathrm{E}_{2}\right)$ production and $\mathrm{E}_{2}$-mediated negative feedback on pituitary LH secretion. Aromatase inhibitors can reverse this process. This study evaluates whether letrozole once a week can normalize serum testosterone in severely obese men and maintain its long term effect.

Design: Open, uncontrolled 6-month pilot study in 12 severely obese men (body mass index > $35.0 \mathrm{~kg} / \mathrm{m}^{2}$ ) with obesity-related IHH and free testosterone levels $<225 \mathrm{pmol} / \mathrm{l}$, treated with $2.5 \mathrm{mg}$ letrozole once a week for 6 months.

Results: Six weeks of treatment reduced total $\mathrm{E}_{2}$ from $123 \pm 11$ to $58 \pm 7 \mathrm{pmol} / \mathrm{l}(P<0.001$, mean \pm S.E.M.), and increased serum LH from $4.4 \pm 0.6$ to $11.1 \pm 1.5 \mathrm{U} / \mathrm{l}(P<0.001)$. Total testosterone rose from $5.9 \pm 0.5$ to $19.6 \pm 1.4 \mathrm{nmol} / \mathrm{l}(P<0.001)$, and free testosterone from $163 \pm 13$ to $604 \pm$ $50 \mathrm{pmol} / \mathrm{l}(P<0.001)$. Total testosterone rose to within the normal range in all subjects, whereas free testosterone rose to supraphysiological levels in 7 out of 12 men. The testosterone and $\mathrm{E}_{2}$ levels were stable throughout the week and during the 6-month treatment period.

Conclusion: Letrozole $2.5 \mathrm{mg}$ once a week produced a sustained normalization of serum total testosterone in obese men with IHH. However, free testosterone frequently rose to supraphysiological levels. Therefore, a starting dose $<2.5 \mathrm{mg}$ once a week is recommended.
\end{abstract}

European Journal of Endocrinology 158 741-747

\section{Introduction}

Morbid obesity can be associated with biochemical evidence of isolated hypogonadotropic hypogonadism (IHH) $(1,2)$. Its occurrence is proportional to the degree of overweight $(3,4)$. In a recent study, IHH was observed in $36 \%$ of 160 men who were referred for medical or surgical obesity treatment. The prevalence rose linearly, from $7.4 \%$ in body mass index (BMI) category $30-35 \mathrm{~kg} / \mathrm{m}^{2}$ to $59.2 \%$ in BMI category $>50 \mathrm{~kg} / \mathrm{m}^{2}(4)$.

Obesity-related $\mathrm{IHH}$ has been attributed to luteinizing hormone (LH) suppressive effects of estrogen excess, leptininduced inhibition of LH secretion, and hypothalamicpituitary dysfunction caused by obstructive sleep apnea (3-6). The present study is focused on the consequences of estrogen excess because the enhanced, aromatasedependent conversion of testosterone to estradiol $\left(\mathrm{E}_{2}\right)$ in the adipocyte may be a key abnormality in obesity-related $\mathrm{IHH}$ (7). It has been established that the elevated serum $\mathrm{E}_{2}$ levels inhibit pituitary LH secretion and thereby reduce serum testosterone in adult men (8-10). Two pilot studies have shown that aromatase inhibitors can reverse this chain of events $(11,12)$. Both of these studies reported a marked reduction in serum estrogens, and a large increase in $\mathrm{LH}$ and testosterone. However, the optimal dose to normalize the estrogen-androgen balance remains to be established.

At present it is not known whether normalization of serum testosterone is beneficial in obesity-related IHH. Extrapolation of the effects of testosterone replacement in non-obese or overweight hypogonadal men is hazardous because the results may prove to be markedly different in severe obesity $(13,14)$. Due to the high conversion of testosterone to $\mathrm{E}_{2}$, testosterone replacement is likely to raise serum $\mathrm{E}_{2}$ levels considerably and this may produce clinically relevant adverse effects. Therefore, it may be useful to explore the pros and cons of alternative modes of treatment, such as the use of aromatase inhibitors. In theory, the main risks of this treatment are excessive reduction of estrogen levels, which could adversely affect bone metabolism, and overstimulation of LH secretion, which could lead to supraphysiological testosterone levels. However, aromatase inhibition may also have new advantageous effects because of its stimulatory effects on follicle-stimulating hormone (FSH) secretion. This could be of benefit in the case of reduced fertility, which is common in severely obese men $(15,16)$.

Before considering clinical efficacy studies, the safety limits of aromatase inhibition need to be defined more 
precisely to prevent adverse effects related to lack of experience with appropriate dose titration. Information is also needed regarding the long-term efficacy of aromatase inhibitors to maintain the gonadal hormone levels within the normal range. So far, only short-term experience is available. The present study was performed to evaluate whether a low dose of letrozole, administered once a week for a period of 6 months, can produce normal and stable serum levels of testosterone and $E_{2}$.

\section{Patients and methods}

\section{Subjects}

Twelve men with acquired, obesity-related IHH were included in the study. IHH was detected because measurement of serum testosterone is part of the screening procedure in our clinic for obese men who apply for medical or surgical obesity treatment (4). The diagnosis of $\mathrm{IHH}$ was based on the following biochemical criteria: serum-free testosterone $<225 \mathrm{pmol} / \mathrm{l}$, associated with an inappropriately low serum LH $<9.0 \mathrm{U} / \mathrm{l}$, and without evidence of intercurrent disease or additional pituitary hormone deficiencies, metabolic disorders, or medications known to affect the gonadal axis. Additional pituitary hormone deficiencies were considered to be absent if thyrotrophin, free thyroxine, prolactin, adrenocorticotrophin, cortisol, and insulinlike growth factor-I levels were within the normal range. Pituitary hormone stimulation tests were not performed. All subjects had a normal pubertal development and intact sense of smell. Testicular size was within the normal range. Hemochromatosis was excluded by the measurement of serum transferrin saturation and ferritin levels. Hepatic and renal functions were normal. Body weight exceeded the scan's weight limit of $140 \mathrm{~kg}$ in 7 subjects, therefore, a pituitary magnetic resonance imaging could be performed in only 5 out of the 12 subjects. Their scans showed normal pituitary and hypothalamic structures. The mean age of the men included in the study was $48.4 \pm 3.3$ (range 34.5-64.6 years), with a mean BMI of $45.7 \pm 3.0 \mathrm{~kg} / \mathrm{m}^{2}$ (range $37.2-67.4 \mathrm{~kg} / \mathrm{m}^{2}$ ). Of the 12 patients, 7 had erectile dysfunction and libido was decreased in 6 subjects. There was no clinical evidence of prostate disease (normal rectal examination and normal prostate-specific antigen (PSA)). Of the five patients with type 2 diabetes, three required insulin therapy. Two men were on CPAP for sleep apnea, two men had a myocardial infarction at least 5 years ago, two subjects were successfully treated for hypertension with a combination of $\beta$-blockers, diuretics, and angiotensin converting enzyme (ACE) inhibitors, and two subjects used statins. None were using medication known to affect the pituitary-gonadal axis. All subjects were instructed to maintain their usual lifestyle as before, and to postpone any attempt to weight loss until the completion of the present study.
The study was approved by the local ethical committee, and all subjects gave their informed consent.

\section{Protocol}

All blood samples were taken in the morning between 0800 and $1000 \mathrm{~h}$. After taking the basal measurements, letrozole was started in a dose of $2.5 \mathrm{mg}$ once a week, taken orally, on Monday before breakfast. Blood sampling was repeated, on Wednesday, after 6 weeks and 6 months of treatment. At 6 weeks, additional morning samples were taken on Friday and Monday to determine whether the serum testosterone levels were stable throughout the week. The Monday blood sample was taken before ingestion of the next dose of letrozole.

\section{Assays, calculations, and statistics}

Measurement of serum LH, FSH, total testosterone, and total $\mathrm{E}_{2}$ was performed by electrochemiluminescene immunoassay (Roche Diagnostics). The reference ranges were: total testosterone, 11-28 nmol/l; $\mathrm{E}_{2},<160 \mathrm{pmol} / \mathrm{l}$ (detection limit $40 \mathrm{pmol} / \mathrm{l}$ ); LH, 2.09.0 U/l; and FSH, 1.5-12.4 U/l. Sex hormone binding globulin (SHBG) was measured by chemiluminescent enzyme immunoassay (DPC, Los Angeles, CA, USA, reference range $13-71 \mathrm{nmol} / \mathrm{l})$. Calculation of free testosterone was based on the approach described by Vermeulen et al. (17). Free $\mathrm{E}_{2}$ was calculated with the method of Sodergard et al. (18). The normal ranges were: free testosterone $225-625 \mathrm{pmol} / \mathrm{l}$ and free $\mathrm{E}_{2}$ 1.1-4.7 pmol/l respectively. The validity of the reference ranges was confirmed by in-house measurement of samples obtained from 207 healthy men, ranging in age from 20 to 60 years. Safety data included measurement of HbA1c, PSA, the bone formation marker carboxyterminal propeptide of type I procollagen (PINP, Orion Diagnostics, Espoo, Finland, reference range 20-76 $\mu / \mathrm{l}$ ), and the bone resorption marker carboxy-terminal crosslinked telopeptide of type I collagen (ICTP, Orion Diagnostics, reference range 1.8-5.0 $\mu \mathrm{g} / \mathrm{l}$ ).

Results are expressed as mean values and s.E.M. The samples with total $\mathrm{E}_{2}$ levels below the detection limit $(40 \mathrm{pmol} / \mathrm{l})$ were given a value of $20 \mathrm{pmol} / \mathrm{l}$ for statistical purposes. Calculations were performed with the statistical package Graphpad Instat (GraphPad Software, San Diego, CA, USA). Data with a normal distribution were evaluated by ANOVA and paired $t$-test, and data not following a normal distribution were tested by Wilcoxon matchedpairs signed-ranks test. $P<0.05$ was considered to be statistically significant.

\section{Results}

Changes in the serum hormone levels after 6 weeks and 6 months of treatment are summarized in Table 1. Individual responses after 6 weeks of treatment are 
Table 1 Serum hormone levels in obese men with isolated hypogonadotropic hypogonadism (IHH), before and after treatment with letrozole for 6 weeks and 6 months respectively.

\begin{tabular}{|c|c|c|c|c|}
\hline & Basal & 6 weeks & 6 months & Reference range \\
\hline LH & $4.4 \pm 0.6$ & $11.1 \pm 1.5^{*}$ & $11.1 \pm 1.6^{*}$ & 2-9 U/I \\
\hline $\mathrm{FSH}$ & $4.8 \pm 0.8$ & $12.1 \pm 1.5^{*}$ & $13.2 \pm 2.1^{*}$ & $1.5-12.4 \mathrm{U} / \mathrm{I}$ \\
\hline Prolactin & $308 \pm 40$ & $282 \pm 22$ & $275 \pm 40$ & $86-324 \mathrm{mU} / \mathrm{l}$ \\
\hline Total testosterone & $5.9 \pm 0.5$ & $19.6 \pm 1.4^{*}$ & $19.5 \pm 1.5^{\star}$ & $11-28 \mathrm{nmol} / \mathrm{l}$ \\
\hline Free testosterone & $167 \pm 18$ & $604 \pm 50^{*}$ & $610 \pm 51^{*}$ & $225-625 \mathrm{pmol} / \mathrm{l}$ \\
\hline Total estradiol & $123 \pm 11$ & $57 \pm 7^{\dagger}$ & $76 \pm 8^{\dagger}$ & $40-160 \mathrm{pmol} / \mathrm{l}$ \\
\hline Free estradiol & $3.8 \pm 0.3$ & $1.8 \pm 0.2^{*}$ & $2.5 \pm 0.3^{\dagger}$ & $1.1-4.7 \mathrm{pmol} / \mathrm{l}$ \\
\hline $\mathrm{FE} / \mathrm{FT}$ ratio $\left(\times 10^{-3}\right)$ & $29.2 \pm 8.2$ & $3.4 \pm 0.6^{*}$ & $4.1 \pm 0.4^{*}$ & $4.8-13.4$ \\
\hline SHBG & $16.7 \pm 1.8$ & $16.9 \pm 2.2$ & $16.4 \pm 1.4$ & $13-71 \mathrm{nmol} / \mathrm{l}$ \\
\hline Albumin & $41.1 \pm 0.8$ & $41.4 \pm 0.9$ & $40.8 \pm 1.2$ & $35-50 \mathrm{~g} / \mathrm{l}$ \\
\hline $\mathrm{HbA1c}$ & $6.8 \pm 0.5$ & - & $6.7 \pm 0.5$ & $4.0-6.0 \%$ \\
\hline PSA & $0.9 \pm 0.2$ & - & $1.2 \pm 0.2$ & $<4.1 \mu \mathrm{g} / \mathrm{l}$ \\
\hline PINP & $48.7 \pm 5.1$ & - & $46.9 \pm 5.8$ & $20-76 \mu \mathrm{g} / \mathrm{l}$ \\
\hline ICTP & $5.0 \pm 0.7$ & - & $7.6 \pm 1.2^{\ddagger}$ & $1.8-5.0 \mu \mathrm{g} / \mathrm{l}$ \\
\hline
\end{tabular}

Results in mean \pm S.E.M. ${ }^{\star} P<0.001,{ }^{\dagger} P<0.005$, and ${ }^{\ddagger} P<0.05$ for the comparison with basal levels.

shown in Fig. 1. The basal LH levels were detectable, but were inappropriately low for the degree of reduction in serum testosterone. Pretreatment total testosterone ranged from 2.1 to $8.9 \mathrm{nmol} / \mathrm{l}$ (normal range 11-28 nmol/l), SHBG from 7 to $27 \mathrm{nmol} / \mathrm{l}$ (normal range $13-71 \mathrm{nmol} / \mathrm{l})$, and calculated free testosterone from 51 to $216 \mathrm{pmol} / \mathrm{l}$ (normal range $225-625 \mathrm{pmol} / \mathrm{l}$ ). Of the $12 \mathrm{men}, 8 \mathrm{had}$ free testosterone $<180 \mathrm{pmol} / \mathrm{l}$. Despite the marked reduction in serum testosterone, most total and free $E_{2}$ levels were in the upper half of the reference range. The levels of total and free $\mathrm{E}_{2}$ exceeding the upper normal limit were observed in 1 and 2 subjects respectively. The ratio of free $E_{2} /$ free testosterone was markedly increased in all subjects (mean value $29.2 \pm 8.2$, normal range 4.8-13.4).

The serum albumin or SHBG levels were not affected by the 6 weeks treatment. Total $\mathrm{E}_{2}$ decreased from $123 \pm 11$ to $57 \pm 8 \mathrm{pmol} / \mathrm{l}$. In three subjects total $\mathrm{E}_{2}$ fell below the assay detection limit of $40 \mathrm{pmol} / \mathrm{l}$. Free $\mathrm{E}_{2}$ levels decreased from $3.8 \pm 0.3$ to $1.8 \pm 0.2 \mathrm{pmol} / \mathrm{l}$ $(P<0.001)$. Mean LH concentration increased from $4.4 \pm 0.6$ to $11.1 \pm 1.5 \mathrm{U} / \mathrm{l}(P<0.001)$. FSH rose from
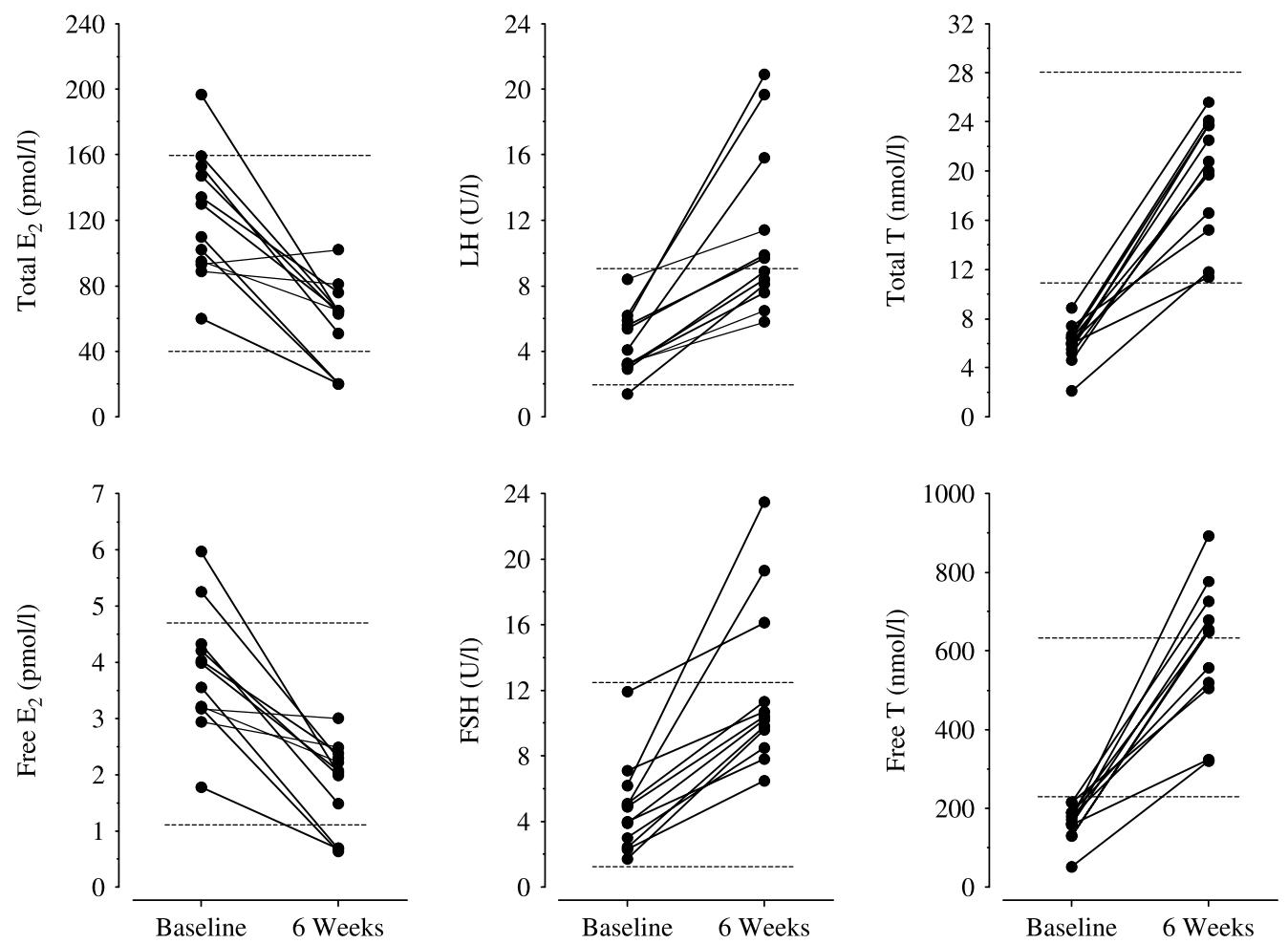

Figure 1 Serum hormone levels in severely obese men with $\mathrm{IHH}$, before and after treatment with letrozole $2.5 \mathrm{mg}$ once a week for a period of 6 weeks. The dotted lines represent the normal limits. T, testosterone; $E_{2}$, estradiol. 
$4.8 \pm 0.5$ to $12.1 \pm 1.5 \mathrm{U} / \mathrm{l}(P<0.001)$. $\mathrm{LH}$ and $\mathrm{FSH}$ levels exceeded the upper normal limit in six and three men respectively. Mean total testosterone rose from $5.9 \pm 0.5$ to $19.6 \pm 1.4 \mathrm{nmol} / \mathrm{l} \quad(P<0.001)$ and free testosterone from $163 \pm 13$ to $604 \pm 50 \mathrm{pmol} / \mathrm{l}$ $(P<0.001)$. In all the subjects, total testosterone rose to within the normal range. In six subjects, the free testosterone levels exceeded the upper normal limit and in four of them this was associated with LH levels above the normal limit. Blood samples taken on the Wednesday, Friday, and Monday showed relatively stable mean LH, FSH, testosterone, $\mathrm{E}_{2}$, SHBG, and albumin levels throughout the week (Fig. 2A-E, albumin not shown). The small increase in total $E_{2}$ and the small decrease in LH that occurred over the week were statistically not significant. Individual measurements of testosterone levels throughout the week are shown in Fig. 2F. Hormone levels achieved at 6 weeks remained stable during the 6-month observation period (Table 1).

The safety parameters $\mathrm{HbA1c}$, PSA, and PINP did not change. ICTP increased from $5.0 \pm 0.7$ to $7.6 \pm 1.2 \mu \mathrm{g} / \mathrm{l}$ $(P<0.05)$.

\section{Discussion}

The results of this study confirm that the aromatase inhibitor letrozole is a potent agent to stimulate $\mathrm{LH}$ secretion in men with obesity-related IHH. A dose of $2.5 \mathrm{mg}$ once a week normalized serum total testosterone in all subjects, within 6 weeks. Although body weight was not measured during this period, a major effect on hormone levels caused by changes in body weight is very unlikely. Hormonal changes of this magnitude would have required massive weight loss within this brief period. This did not occur as none of the subjects received any anti-obesity treatment during the course of the study. A bias caused by regression to the mean cannot be excluded completely because of the uncontrolled nature of this study. However, in view of the magnitude of the effects and the consistency of the changes in each individual this is not likely to have contributed significantly.

This study has also shown that the achieved testosterone levels were stable throughout the week, and that they remained at the same level during a 6-month observation period. Total $\mathrm{E}_{2}$ decreased significantly and fell below the assay detection limit in 3 out of 12 subjects. The data suggest that letrozole in a dose of $2.5 \mathrm{mg}$ once a week is an acceptable starting dose for most obese men. However, some subjects may require a lower dose to prevent excessive suppression of serum $E_{2}$.

At present, we do not know what the best biochemical marker is to monitor aromatase inhibition in obese men. Exclusively relying on total testosterone is unlikely to be sufficient. It is generally recommended to measure or calculate bioavailable or free testosterone in case of gross abnormalities in sex hormone-binding capacity, and this definitely applies to severely obese men where the SHBG levels are substantially reduced (19). To avoid overestimation of the degree of biochemical hypogonadism in the untreated state, it is recommended to rely on free testosterone instead of total testosterone. In a recent study, this procedure reduced the prevalence of obesity-related IHH from 57.7 to $35.6 \%$ (4).

Gross abnormalities in the SHBG levels also affect the evaluation of treatment effects. If assessment is
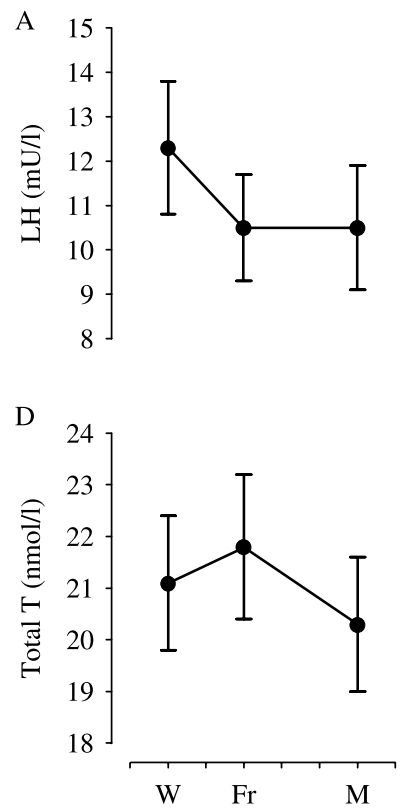
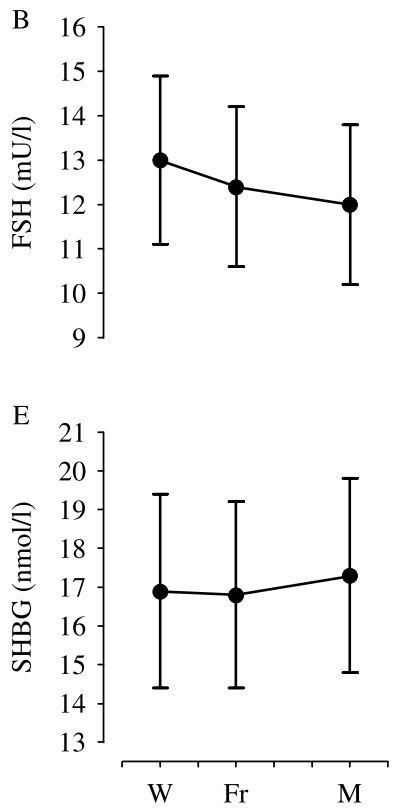

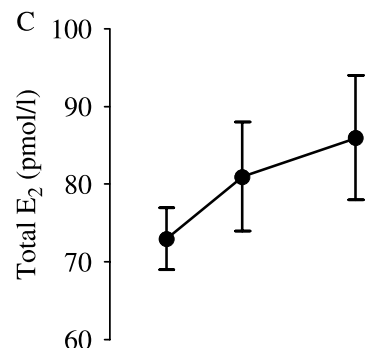

F

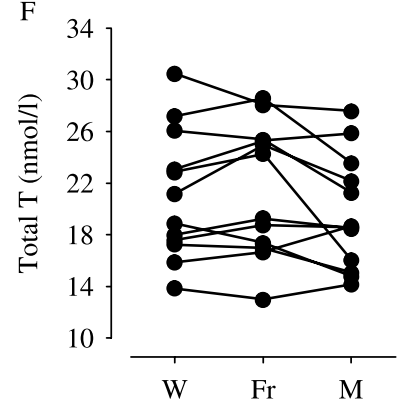

Figure $2(\mathrm{~A}-\mathrm{F})$ Serum hormone and SHBG levels throughout the week during letrozole treatment, measured between 0800 and $1000 \mathrm{~h}$, on Wednesday (W), Friday (Fr), and Monday (M). T, testosterone; $E_{2}$, estradiol. 
exclusively based on the total testosterone levels alone, the effects of treatment will be underestimated. Even in this small study the SHBG pitfall was apparent. Total testosterone rose from a value below the lower normal limit to a level within the normal range in all men, suggesting that the $2.5 \mathrm{mg}$ weekly dose was appropriate. However, free testosterone changed from subnormal to supraphysiological levels in 6 out of 12 subjects, suggesting that dose reduction would be required in case of long-term treatment. The discrepancy is caused by the low and unchanging SHBG levels. In such cases, total testosterone levels in the high normal range will represent androgen excess. Therefore, the most rational and safe monitoring procedure during letrozole treatment in obese men is to aim at normalization of the free testosterone levels instead of total testosterone.

The question of what exactly represents a safe upper normal limit of free testosterone is difficult to answer, and bears the same uncertainties as the definition of the lower normal limit. Vermeulen et al. presented several arguments to base the lower normal limit on measurements performed in healthy adult men in the prime of their life (20-40 years) (20). A recently published guideline supports this approach (21). It is attractive to follow the same line of thought when attempting to define the upper normal limit for serum testosterone. This approach appears to be the most recommendable, at least until better guidelines are available. Clinical signs and symptoms are not likely to be sufficiently sensitive to serve this purpose.

In addition to guarding the upper normal limit of serum-free testosterone, it will be of equal importance to monitor the serum $\mathrm{E}_{2}$ levels during treatment with letrozole. As observed in this study, even a low dose of letrozole reduced serum total $\mathrm{E}_{2}$ to a value below the detection limit in 3 out of 12 men after 6 weeks of treatment. Free testosterone and LH levels were supraphysiological in two of these men. At 6 months, total $E_{2}$ was undetectable in only one subject who had a normal free testosterone and LH level. Although the current data are too limited for firm conclusions, they do suggest that monitoring of aromatase inhibition in men by free testosterone and $\mathrm{LH}$ alone may not be sufficient. Excessive estrogen suppression might be missed. It is important to avoid excessive estrogen suppression. Several case reports on congenital aromatase deficiency in men have clearly demonstrated that bone metabolism is abnormal in estrogen-deficient men (22-24). In adult men, the main risk is development of osteoporosis. Other adverse effects related to prolonged and severe estrogen deficiency in men are not known. At present, we do not know exactly above which level the serum $\mathrm{E}_{2}$ should be maintained to avoid adverse effects. Observations in elderly men suggest that the levels of bioavailable $\mathrm{E}_{2}$ should be maintained above $40 \mathrm{pmol} / \mathrm{l}$ (25). To further explore this area, more sensitive $\mathrm{E}_{2}$ assays, than were used in this study should be employed.
Current experience with aromatase inhibition in males is limited. The available data suggest that harmful effects are dose dependent and that major adverse effects are unlikely if the dose is carefully adjusted based on measurement of the serum testosterone and $E_{2}$ levels (26-34). Letrozole $2.5 \mathrm{mg}$ /day has been used successfully to increase predicted adult height in testosteronetreated boys with constitutional delay of puberty. The effect was attributed to delayed bone maturation by inhibition of estrogen synthesis and action (26). Although letrozole tended to decrease the activation of bone metabolism as indicated by the serum PINP and ICTP levels, 1-year treatment did not adversely affect bone mass accretion (27). Letrozole reduced the fasting insulin levels and decreased high density lipoprotein (HDL) cholesterol. It remained unclear whether the reduction in HDL was related to the excessive rise in serum testosterone or to the reduction in $\mathrm{E}_{2}$ that occurred in the letrozole-treated group (28). In adult men, most experience has been gained with anastrozole. A 10-week study with anastrozole $7 \mathrm{mg}$ weekly in four late-pubertal boys and four young adults did not reveal effects on serum bone markers, bone density, body composition measured by bioelectrical impedance, skinfold measurements, or on muscle strength (29). A dose of 2-7 mg anastrozole weekly for 3 months in 23 partially androgen-deficient elderly men, age range 62-74 years, did not affect biochemical markers of bone turnover nor total body bone mineral density (30, 31). By contrast, a 9-week study in 15 eugonadal elderly men using anastrozole $14 \mathrm{mg}$ weekly caused an increase in bone resorption markers and a decrease in bone formation markers (32). This dose should be considered as potentially harmful, unless firmer end points demonstrate differently. Letrozole $2.5 \mathrm{mg}$ per day has been used in a 28-day study in young and elderly man to examine the $E_{2}$ negative feedback on gonadotropin secretion, but this study did not evaluate metabolic effects (35). In this study, we monitored the effects on HbAlc, PINP, ICTP, and PSA for 6 months. The bone resorption marker ICTP increased slightly, the other variables did not change significantly. Although the clinical significance of this observation remains to be demonstrated, it suggests that some serum markers reflecting tissue activity may provide useful information to guide treatment.

To assess the minimal effective dose of letrozole in men, it is useful to recapitulate the results of an open dosefinding study in healthy non-obese male volunteers (age range 20-48 years) that explored the effects of single doses of letrozole ranging from 0.02 to $30 \mathrm{mg}$ (36). Suppression of estrogen levels and increases in serum LH and testosterone were observed after a single dose of letrozole as low as $0.02 \mathrm{mg}$, with effects lasting for about $48 \mathrm{~h}$. The effects of a single dose of $0.5 \mathrm{mg}$ lasted for at least 3 days. We recommend that this $0.5 \mathrm{mg}$ dose should be included in future dose-finding studies. We speculate that a twice weekly dose of $0.5 \mathrm{mg}$ may be sufficient to normalize the estrogen-androgen balance in most obese men. 
Letrozole treatment was also associated with a substantial increase in FSH levels. A similar response has been observed in non-obese healthy men $(10,35)$. The effect is attributed to a reduction of $E_{2}$ 's negative feedback on hypothalamic gonadotrophin-releasing hormone secretion. As recent reports indicate that fertility is reduced in overweight and obese men, the FSH response to aromatase inhibition may serve to improve fertility $(15,37)$. The aromatase inhibitors have been successfully used in (eugonadal) subfertile, oligospermic men and were shown to improve sperm quantity and quality (16). To date, the effect on semen production in subfertile obese men is not known.

In conclusion, letrozole once a week can normalize serum testosterone in men with obesity-related IHH. The observed increase in serum testosterone is of sufficient magnitude to be of clinical interest, and the response was sustained with ongoing treatment without a loss of effect. The key question is whether obese men with IHH truly suffer from low androgen levels, whether restoration of the normal estrogen-androgen balance is of any benefit and what would be the most appropriate way of treatment. Although this study indicates that aromatase inhibition is a feasible option to correct the abnormalities in serum gonadal hormone levels in obese men, its clinical relevance and safety remain to be demonstrated.

\section{References}

1 Glass AR, Swerdloff RS, Bray GA, Dahms WT \& Atkinson RL. Low serum testosterone and sex-hormone-binding-globulin in massively obese men. Journal of Clinical Endocrinology and Metabolism 197745 1211-1219.

2 Amatruda JM, Harman SM, Pourmotabbed G \& Lockwood DH. Depressed plasma testosterone and fractional binding of testosterone in obese males. Journal of Clinical Endocrinology and Metabolism $197847268-271$.

3 Zumoff B, Strain GW, Miller LK, Rosner W, Senie R, Seres DS \& Rosenfeld RS. Plasma free and non-sex-hormone-binding globulinbound testosterone are decreased in obese men in proportion to their degree of obesity. Journal of Clinical Endocrinology and Metabolism 199071 929-931.

4 Hofstra J, Loves S, van Wageningen B, Ruinemans-Koerts J, Janssen I \& de Boer H. High prevalence of hypogonadotropic hypogonadism in men referred for obesity treatment. Netherlands Journal of Medicine $2008 \mathbf{6 8} 13-19$.

5 Isidori AM, Caprio M, Strollo F, Moretti C, Frajese G, Isidori A \& Fabbri A. Leptin and androgens in male obesity: evidence for leptin contribution to reduced androgen levels. Journal of Clinical Endocrinology and Metabolism 199984 3673-3680.

6 Luboshitzky R, Aviv A, Hefetz A, Herer P, Shen-Orr Z, Lavie L \& Lavie P. Decreased pituitary-gonadal secretion in men with obstructive sleep apnea. Journal of Clinical Endocrinology and Metabolism 200287 3394-3398.

7 Schneider G, Kirschner MA, Berkowitz R \& Ertel NH. Increased estrogen production in obese men. Journal of Clinical Endocrinology and Metabolism 197948 633-638.

8 Bagatell CJ, Dahl KD \& Bremmer WJ. The direct pituitary effect of testosterone to inhibit gonadotropin secretion in men is partially mediated by aromatization to estradiol. Journal of Andrology 199415 $16-21$.
9 Giagulli VA, Kaufman JM \& Vermeulen A. Pathogenesis of the decreased androgen levels in obese men. Journal of Clinical Endocrinology and Metabolism 199479 997-1000.

10 Hayes FJ, Seminara SB, Decruz S, Boepple PA \& Crowley WF. Aromatase inhibition in the human male reveals a hypothalamic site of estrogen feedback. Journal of Clinical Endocrinology and Metabolism 200085 3027-3035.

11 Zumoff B, Miller LK \& Strain GW. Reversal of the hypogonadotropic hypogonadism of obese men by administration of the aromatase inhibitor testolactone. Metabolism 200352 1126-1128.

12 De Boer H, Verschoor L, Ruinemans-Koerts J \& Jansen M. Letrozole normalizes serum testosterone in severely obese men with hypogonadotropic hypogonadism. Diabetes, Obesity and Metabolism 20057 211-215.

13 Rhoden EL \& Morgentaler A. Risks of testosterone-replacement therapy and recommendations for monitoring. New England Journal of Medicine $2004350482-492$.

14 Bhasin S, Cunningham GR, Hayes FJ, Matsumoto AM, Snyder PJ, Swerdloff RS \& Montori VM. Testosterone therapy in adult men with androgen deficiency syndromes: an endocrine society clinical practice guideline. Journal of Clinical Endocrinology and Metabolism 200691 1995-2010.

15 Sallmen M, Sandler DP, Hoppin JA, Blair A \& Baird DD. Reduced fertility among overweight and obese men. Epidemiology 200617 520-523.

16 Raman JD \& Schlegel PN. Aromatase inhibitors for male infertility. Journal of Urology 2002167 624-629.

17 Vermeulen A, Verdonck L \& Kaufman JM. A critical evaluation of simple methods for the estimation of free testosterone in serum. Journal of Clinical Endocrinology and Metabolism 199984 3666-3672.

18 Sodergard R, Backstrom T, Shambag V \& Carstensen H. Calculation of free and bound fractions of testosterone and estradiol to human plasma proteins at body temperature. Journal of Steroid Biochemistry 1982 16 801-810.

19 Vermeulen A, Kaufman JM \& Giaguli VA. Influence of some biological indexes on serum sex hormone binding globulin and androgen levels in aging or obese males. Journal of Clinical Endocrinology and Metabolism 199681 1821-1826.

20 Vermeulen A \& Kaufman JM. Diagnosis of hypogonadism in the aging male. Aging Male 20025 170-176.

21 Nieschlag E, Swerdloff R, Behre HM, Gooren LJ, Kaufman JM, Legros JJ, Lunenefeld B, Morley JE, Schulman C, Wang C, Weidner W \& Wu FCW. Investigation, treatment and monitoring of late-onset hypogonadism in males: ISA, ISSAM and EAU recommendations. Journal of Andrology 200627 135-137.

22 Morishima A, Grumbach MM, Simpson ER, Fisher C \& Qin K. Aromatase deficiency in male and female siblings caused by a novel mutation and the physiological role of estrogens. Journal of Clinical Endocrinology and Metabolism 199580 3689-3698.

23 Carani C, Qin K, Simoni M, Faustini-Fustini M, Serpente S, Boyd J, Korach KS \& Simpson ER. Effect of testosterone and estradiol in a man with aromatase deficiency. New England Journal of Medicine 1997337 91-95.

24 Bilezkian JP, Morishima A, Bell J \& Grumbach M. Increased bone mass as a result of estrogen therapy in a man with aromatase deficiency. New England Journal of Medicine 1998339 599-603.

25 Khosla S, Melton J, Atkinson EJ \& O'Fallon WM. Relationship of serum sex steroid levels to longitudinal changes in bone density in young versus elderly men. Journal of Clinical Endocrinology and Metabolism 200186 3555-3561.

26 Wickman S, Sipilä L, Ankarberg C, Norjavaara E \& Dunkel L. A specific aromatase inhibitor and potential increase in adult height in boys with delayed puberty: a randomized controlled trial. Lancet 2001357 1743-1748.

27 Wickman S, Kajantie E \& Dunkel L. Effects of suppression of estrogen action by the $\mathrm{P} 450$ aromatase inhibitor Letrozole on bone mineral density and bone metabolism in pubertal boys. Journal of Clinical Endocrinology and Metabolism $2003 \mathbf{8 8}$ 3785-3793. 
28 Wickman S, Saukkonen T \& Dunkel L. The role of sex steroids in the regulation of insulin sensitivity and serum lipid concentrations during male puberty: a prospective study with a P450-aromatase inhibitor. European Journal of Endocrinology 2002146 339-346.

29 Mauras N, O’Brien KO, Oerter Klein K \& Hayes V. Estrogen suppression in males: metabolic effects. Journal of Clinical Endocrinology and Metabolism $2000852370-2377$.

30 Leder BZ, Rohrer JL, Rubin SD, Gallo J \& Longcope C. Effects of aromatase inhibition in elderly men with low or borderline-low serum testosterone levels. Journal of Clinical Endocrinology and Metabolism 200489 1174-1180.

31 Leder BZ \& Finkelstein JS. Effects of aromatase inhibition in elderly hypogonadal men, Osteoporosis International 200516 1487-1494.

32 Taxel P, Kennedy DG, Fall PM, Willard AK, Clive JM \& Raisz LG. The effect of aromatase inhibition on sex steroids, gonadotropins and markers of bone turnover in older men. Journal of Clinical Endocrinology and Metabolism 200186 2869-2874.

33 Simpson ER, Misso M, Hewitt KN, Hill RA, Boon WC, Jones ME, Kovacic A, Zhou J \& Clyne CD. Estrogen-the good, the bad, and the unexpected. Endocrine Reviews $200526322-330$.
34 De Ronde W. Therapeutic uses of aromatase inhibitors in men. Current Opinion in Endocrinology, Diabetes and Obesity $2007 \mathbf{1 4}$ 235-240.

35 Tsjoen GG, Giagulli VA, Delva H, Crabbe P, De Bacquer D \& Kaufman JM. Comparative assessment in young and elderly men of the gonadotropin response to aromatase inhibition. Journal of Clinical Endocrinology and Metabolism 200590 5717-5722.

36 Trunet PF, Mueller P, Bhatnagar AS, Dickes I, Monnet G \& White G. Open dose-finding study of a new potent and selective nonsteroidial aromatase inhibitor, CGS 20267, in healthy male subjects. Journal of Clinical Endocrinology and Metabolism 199377 319-323.

37 Kort HI, Massey JB, Elsner CW, Mitchell-Leef D, Shapiro DB, Witt MA \& Roudebush WE. Impact of body mass index values on sperm quantity ad quality. Journal of Andrology $2006 \mathbf{2 7}$ 450-452.

Received 7 January 2008

Accepted 6 February 2008 